\title{
Carbon Dioxide Emissions by the Transportation Sector and Its Impact on Health in the Kathmandu Valley, Nepal
}

\author{
Kishor Shrestha ${ }^{1}$, Pramen P. Shrestha ${ }^{2}$, and Geeta Shrestha ${ }^{3}$ \\ 1. General Engineering Department, Montana Tech of the University of Montana, Montana 59701, USA \\ 2. Civil and Environmental Engineering and Construction Department, University of Nevada, Las Vegas, Nevada 89154, USA \\ 3. Human Rights Officer, National Human Rights Commission, Harihar Bhawan, Lalitpur, Nepal
}

\begin{abstract}
Air pollution is one of the leading cause of death for underdeveloped as well as developed countries. In 2011, the air pollution was the second leading cause of death in one of the main hospitals of the Kathmandu Valley, Nepal, and it was the third leading cause in the United States. Burning fossil fuels for transportation was one of the major causes. Among various impacts of the air pollution, COPD (chronic obstructive pulmonary disease) was one of the main consequences. In the $570 \mathrm{~km}^{2} \mathrm{Kathmandu}_{\mathrm{Valley}}$, vehicle registration was increased from 45,871 in 1990/1991 to 570,145 in 2010/2011, an increase of over 12-fold over 20 years. The vehicle registration and number of COPD patients' data were collected from various government divisions. In addition, the average daily travel distance and fuel mileage data were collected with a survey with residents of the Kathmandu Valley. This paper calculates the amount of carbon dioxide $\left(\mathrm{CO}_{2}\right)$ emissions by transportation sector and determines correlation between $\mathrm{CO}_{2}$ emissions and COPD patients. Results show that there was a very high level of $\mathrm{CO}_{2}$ emissions, and it was positively correlated with the number of COPD patients in the valley.
\end{abstract}

Key words: Carbon dioxide emissions, health impact, Kathmandu.

\section{Introduction}

According to a 2003 World Bank Report, about 800,000 people die every year in the world due to air pollution [1]. In 2010, in India alone, 620,000 premature deaths occurred due to air pollution related diseases [2]. The NIEHS (National Institute of Environmental Health Sciences) defines air pollution as a "mixture of natural and man-made substances in the air we breathe such as fine particles produced by the burning of fossil fuels...” [3]. According to Holgate et al., five classical air pollutants are carbon oxides $\left(\mathrm{CO}_{\mathrm{x}}\right)$, nitrogen oxides $\left(\mathrm{NO}_{\mathrm{x}}\right)$, sulphur dioxide $\left(\mathrm{SO}_{2}\right)$, volatile organic compounds, and particulate matter [4].

Carbon dioxide $\left(\mathrm{CO}_{2}\right)$ has adverse effects on human health. Rice says the humans who are particularly

Corresponding author: Kishor Shrestha, Ph.D., research fields: performance-based contracting, life-cycle cost analysis, project delivery method, highway safety, and sustainability. E-mail: kshrestha@mtech.edu. sensitive to $\mathrm{CO}_{2}$ are: (1) "cerebral disease and trauma patients”; (2) "individuals performing complex tasks", (3) "infants and children"; (4) "medicated patients"; (5) "panic disorder patients"; and (6) "pulmonary and coronary patients" [5].

The main causes of air pollution in Nepal were number of vehicle increase (14\% annually), urbanization (4-5\% annually), and unplanned industrialization [6]. In the Kathmandu Valley, other causes of air pollution include burning of fossil fuels to drive vehicles, burning fuels in the industries and factories, using high carbon content fuels (2\%), geographical configuration, and forest fires [7-9]. Another cause of air pollution was vehicles that were not regularly maintained; $23 \%$ of vehicles produced greenhouse gases higher than the standard set [8]. Before 2002, the main source of air pollution was the Himal Cement Factory and Brick Kilns while they were in operation [7]. After the cement factory was closed in 2002 and environmentally friendly brick 
kilns were introduced, the main culprit of air pollution in the valley (urbanized area) became vehicle emissions from the transportation sector [4, 7, 10-12]. In a study by CEN (Clean Energy Nepal) and the ENPHO (Environmental and Public Health Organization), the air pollution level was measured on weekdays, weekends, valley strike days, and holidays in the Kathmandu Valley, and researchers concluded that the prime reason of air pollution was vehicle use [7]. Two studies examined the three major contributors of air pollution were transportation, household, and industrial sectors [9, 12]. Both studies showed that the transportation sector was the largest contributor. Shrestha and Rajbhandari estimated the total emission of the three contributors (transportation, household, and industrial sectors) to be 962 kilotons in 2005; and this trend would predict 2,520 kilotons and 4,561 kilotons of $\mathrm{CO}_{2}$ emissions in 2030 and 2050, respectively [9]. The bowl-shaped geography of the Kathmandu Valley plays an important role by keeping air pollutants trapped within the surrounding mountains; this results in the accumulation of the pollutants, and results are therefore more severe $[7,13]$.

To reduce air pollution in the Kathmandu Valley, Dhakal proposed three policies: improving vehicle speed, promoting public transportation, and introducing electric vehicles that could reduce public transportation energy demand by more than $60 \%$ [13]. The author also described the initiatives taken to reduce air pollution in the Valley: (1) banning three-wheeler diesel vehicles; (2) promoting electric vehicles; (3) prohibiting new registration of two-stroke engine vehicles; and (4) setting up vehicle emission standards. The government of Nepal also introduced Euro III emission standard in 2012 [14]. However, due to lack of enforcement on vehicle registration and their emission standards, air pollution was still increasing.

In the transportation sector, emission is due to burning either gasoline or diesel for vehicles. The vehicles were categorized into three types: heavy vehicles, light vehicles, and motorized two-wheelers. Heavy vehicles comprise of public service buses, mini-buses, heavy construction equipment, and trucks; light vehicles comprise of cars, taxis, SUVs, mini-vans, three-wheelers, ambulances, pickups, tractors, and micro-buses; and motorized two-wheelers comprise of motorcycles, scooters, and mopeds. Almost all heavy vehicles use diesel while light vehicles and motorized two-wheelers use gasoline. Due to a large increase in the number of vehicles in the Kathmandu Valley, there was a rapid growth of energy and fuel demand [13]. The author also showed that $\mathrm{CO}_{2}$ emission from gasoline vehicles was nearly two thirds of total $\mathrm{CO}_{2}$ emissions in the valley in 2003. In a 2001 study, fuel consumption for the Valley was $79 \%$ of gasoline and $27 \%$ of diesel [8]. A study conducted by Baidya and Borken-Kleefeld GHG (calculated greenhouse gas) emissions with three metrics - type of fuel used by the vehicles, age or technology used by the vehicles, and vehicle distance travelled annually by each category of vehicles [15]. The results of that study showed the number of motorized two-wheelers was significantly increased in 2005 compared with 1995 data. The increased number of motorized two-wheelers played an important role causing increased congestion [15]. It is also clear that motorized two-wheelers and light vehicles consume more unit fuel per passenger as compared to heavy vehicles or large public buses.

There are various impacts of air pollution on human health; COPD (chronic obstructive pulmonary disease) is one of them [16]. The NIH (National Institutes of Health) defines COPD as "a progressive disease that makes it hard to breathe" [16]. COPD includes emphysema, chronic bronchitis, and asthma [17]. In the USA, respiratory disease, especially COPD, was the third leading cause of death in 2011 [17]. In Nepal, COPD data from one of the oldest hospitals, Bir Hospital, showed that COPD was the second highest cause of morbidity in 2009/2010 [18]. In 2002, 
Brunekreef and Holgate studied the effects of air pollution on its short-term and long-term respiratory effects [19]. The short-term effects were an increase in mortality rate, an increase in hospital admissions of asthma patients, and an increase of COPD in senior citizens. On the other hand, the long-term effects were an increase in morbidity and symptoms of bronchitis.

The primary objective of this study is to determine the amount of $\mathrm{CO}_{2}$ emissions by transportation sector, and to establish a relationship between $\mathrm{CO}_{2}$ emissions and COPD patients. This study also presents the seasonality of the hospital admitted COPD patients. Moreover, this study describes the reasons of $\mathrm{CO}_{2}$ emissions and suggested recommendations to reduce the level of air pollution in the valley.

\section{Materials and Methods}

This study is an extension of previous study of "carbon dioxide emissions by the transportation sector in Kathmandu Valley, Nepal” [20]. In this study, to calculate the $\mathrm{CO}_{2}$ emissions, three parameters were considered. They were type of fuel used, vehicle distance traveled annually, and average vehicle mileage. To calculate the $\mathrm{CO}_{2}$ emissions, the following steps were followed:

(1) The vehicle registration data, which were categorized into three types-heavy vehicles, light vehicles, and motorized two wheelers were collected from the Department of Transport Management Kathmandu;

(2) To determine vehicle mileage and vehicle travel mile per day of the three categorized vehicles, a survey was conducted with valley residents;

(3) The efficiency of older vehicles decreases every year; and so the fuel consumption increases with longer in use. Therefore, to calculate the fuel consumption of older vehicles, the USDOT Bureau of Transportation Statistics data were used as a factor.

The emission standard used in the Kathmandu Valley is different from the US emission standards. However, due to a lack of data, $\mathrm{CO}_{2}$ emission data obtained from the US EPA (Environmental Protection Agency) 2012 was used. According to the EPA, the $\mathrm{CO}_{2}$ emission of diesel was $2.66 \mathrm{~kg} / \mathrm{L}$ (22.2 lbs/gallon) and that of gasoline was $2.33 \mathrm{~kg} / \mathrm{L}$ (19.4 lbs/gallon) $[21,22]$.

\subsection{Data Collection and Analysis}

The motor vehicle data in the Kathmandu Valley were collected from the DMV (Department of Motor Vehicles), Kathmandu, Nepal and from the ICIMOD (International Centre for Integrated Mountain Development) [23]. The vehicle data were collected from 1991 to 2011 and are presented in Table 1. The total number of vehicles increased from 45,871 in $1990 / 1991$ to 570,145 in 2010/2011. The highest number of vehicles type in the valley was motorized two-wheelers.

The vehicle travel mile per day and vehicle mileage data were collected by a survey with drivers. At gas stations, the drivers were asked two questions - on average, how long do they drive daily and how many kilometers their vehicle can run on a litre of fuel they used. Table 2 presents the average vehicle distance travel and vehicle mileage of three types of vehicles.

The amount of fuel consumption (diesel and gasoline) by heavy (diesel vehicles), light (gasoline vehicles), and motorized two-wheelers were calculated separately. Fig. 1 shows the fuel consumed by the three types of vehicles from 1990/1991 to 2010/2011.

Based on the fuel consumption, the total calculated amount of $\mathrm{CO}_{2}$ emission was presented in Fig. 2 . Result showed that the $\mathrm{CO}_{2}$ emission was increasing exponentially. Result showed that for 2009, the $\mathrm{CO}_{2}$ emission was 898 kilotons. In the same year, in New York City, the $\mathrm{CO}_{2}$ emission was 54.35 million tons [24, 25] - a 60 times more. Using the exponential Eq. (1), the total amount of $\mathrm{CO}_{2}$ emission for $2015 / 2016$ is 3.28 million tons.

$\mathrm{CO}_{2}$ was one of the classical air pollutant [4]. To see the consequences of $\mathrm{CO}_{2}$ emission, COPD patient 
Table 1 Number of vehicles registered in the Valley.

\begin{tabular}{|c|c|c|c|c|}
\hline \multirow{2}{*}{ Year } & \multicolumn{3}{|c|}{ Vehicle categories } & \multirow{2}{*}{-Sub-total (\% increase) } \\
\hline & Heavy & Light & 2-wheelers & \\
\hline 1990/1991 & 5,959 & 17,553 & 22,359 & 45,871 \\
\hline 1991/1992 & 6,904 & 18,393 & 28,407 & $53,704(17 \%)$ \\
\hline 1992/1993 & 8,482 & 23,381 & 32,240 & 64,103 (19\%) \\
\hline 1993/1994 & 10,312 & 23,951 & 37,774 & 72,037 (12\%) \\
\hline 1994/1995 & 11,023 & 25,901 & 43,506 & $80,430(12 \%)$ \\
\hline 1995/1996 & 11,686 & 25,676 & 49,299 & $86,661(8 \%)$ \\
\hline 1996/1997 & 12,218 & 30,585 & 58,029 & $100,832(16 \%)$ \\
\hline 1997/1998 & 12,830 & 32,517 & 64,142 & $109,489(9 \%)$ \\
\hline 1998/1999 & 13,199 & 34,706 & 71,612 & 119,517 (9\%) \\
\hline 1999/2000 & 14,267 & 40,051 & 94,217 & 148,535 (24\%) \\
\hline 2000/2001 & 14,854 & 44,824 & 112,000 & $171,678(16 \%)$ \\
\hline 2001/2002 & 16,191 & 47,624 & 134,852 & 198,667 (16\%) \\
\hline 2002/2003 & 17,596 & 50,083 & 156,410 & $224,089(13 \%)$ \\
\hline 2003/2004 & 18,445 & 57,191 & 173,646 & $249,282(11 \%)$ \\
\hline 2004/2005 & 18,810 & 60,402 & 185,593 & $264,805(6 \%)$ \\
\hline 2005/2006 & 20,791 & 66,764 & 205,142 & 292,697 (11\%) \\
\hline 2006/2007 & 23,510 & 75,490 & 231,956 & 330,956 (13\%) \\
\hline 2007/2008 & 26,556 & 85,272 & 262,013 & $373,841(13 \%)$ \\
\hline 2008/2009 & 30,114 & 96,698 & 297,119 & 423,931 (13\%) \\
\hline 2009/2010 & 35,954 & 115,448 & 354,733 & 506,135 (19\%) \\
\hline 2010/2011 & 39,089 & 122,363 & 408,693 & $570,145(13 \%)$ \\
\hline
\end{tabular}

Table 2 Average vehicle distance travel and fuel consumption of vehicles

\begin{tabular}{llll}
\hline Description & Fuel used & Avg. vehicle distance travel $(\mathrm{km} /$ day $)$ & Avg. vehicle mileage $(\mathrm{L} / \mathrm{km})$ \\
\hline Heavy vehicle & Diesel & 154.80 & 9.36 \\
Light vehicle & Gasoline & 40.36 & 12.90 \\
Motorized two-wheeler & Gasoline & 14.00 & 43.25 \\
\hline
\end{tabular}

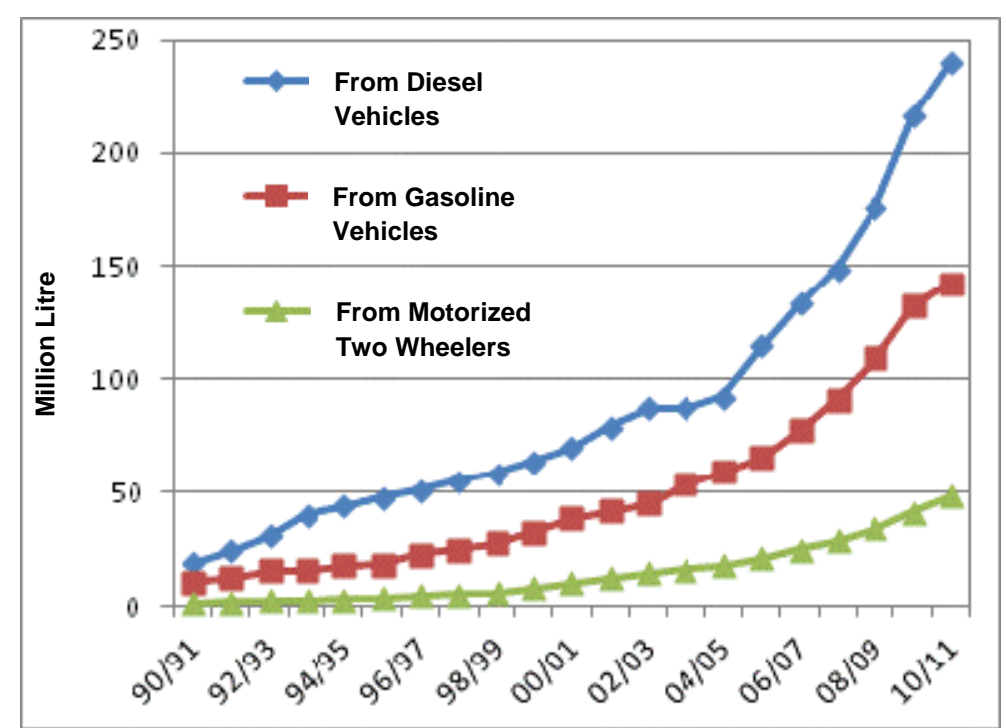

Fig. 1 Calculated fuel consumption by vehicles in the valley. 


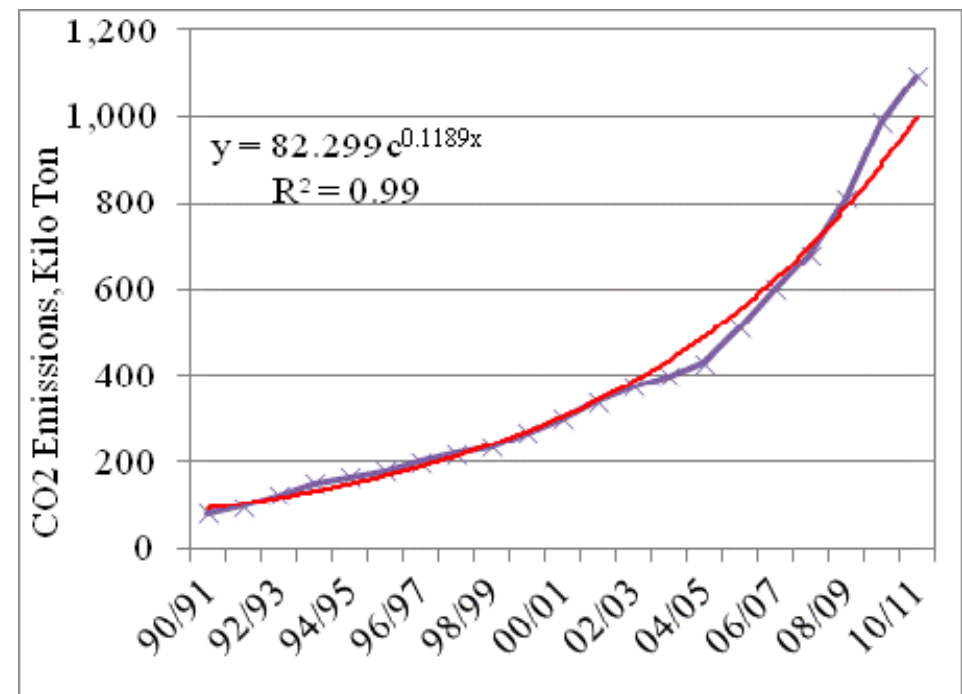

Fig. 2 Calculated emission by vehicles in the valley.

data were observed from 1997/1998 to 2011/2012. The COPD data were collected from the annual reports of the DHS (Department of Health Services) [18]. Among three districts of the Kathmandu Valley, the COPD patient data of Lalitpur district was not available from 2009/2010 to 2011/2012; therefore, the COPD patient data of Kathmandu and Bhaktapur were only considered in this study. Fig. 3 shows the trend of COPD patients admitted. Moreover, population census data and the number of new hospitals opened in the valley were also collected from various sources. The regression model of the increase in $\mathrm{CO}_{2}$ emissions with time can be presented by an exponential Eq. (1), where the variable " $x$ " is the number of years from 1990. To calculate the $\mathrm{CO}_{2}$ emissions for 2017, the value of " $x$ " is 2017 minus 1990 equal to 27 . The model was significant at $95 \%$ confidence interval:

$$
\mathrm{CO}_{2} \text { Emission }=82.299 \times \mathrm{e}^{0.1189 \mathrm{x}}
$$

\subsection{COPD Patient Trend}

The COPD patient data were plotted in Fig. 3. Fig. 3 shows that the number of COPD patients admitted was exponentially increased from 4,136 in $1997 / 1998$ to 19,401 in 2012/2013, respectively [18].

There may be various reasons for increasing COPD patients in the Kathmandu Valley—air pollution, tobacco smoking, exposure to chemicals, and genetics. Also, increasing the population in a city increases the number of COPD patients in that city. The population density of Kathmandu valley was increased from $1,230 / \mathrm{km}^{2}$ to $2,800 / \mathrm{km}^{2}$ from 1991 to 2011 [26, 27]; the population density of Kathmandu metropolitan and municipality was even more-4,386/ $\mathrm{km}^{2}$ in 2009 [28, 29]. The population of the Kathmandu Valley and COPD patients admitted in hospitals from 1997/1998 to 2012/2013 was plotted in Fig. 4. Fig. 4 showed that the increasing COPD patient and population were strongly correlated with $\mathrm{R}^{2}$ value 0.95 .

To see the correlation between $\mathrm{CO}_{2}$ emission and COPD patient admission in hospitals, a graph was plotted between $\mathrm{CO}_{2}$ emissions and COPD patient per 1,000 population, which is presented in Fig. 5. The COPD patient per 1,000 population was used to normalize the effect of increasing population on the number of COPD patient in the valley.

\subsection{The Seasonality in $\mathrm{CO}_{2}$ Emissions and $\mathrm{COPD}$} Patients

Data analysis showed that in 2011, "Teaching Hospital" registered more COPD patients in the winter, and fewer COPD patients in the summer and autumn seasons. In the winter, a blanket-like layer of 

Its Impact on Health in the Kathmandu Valley, Nepal

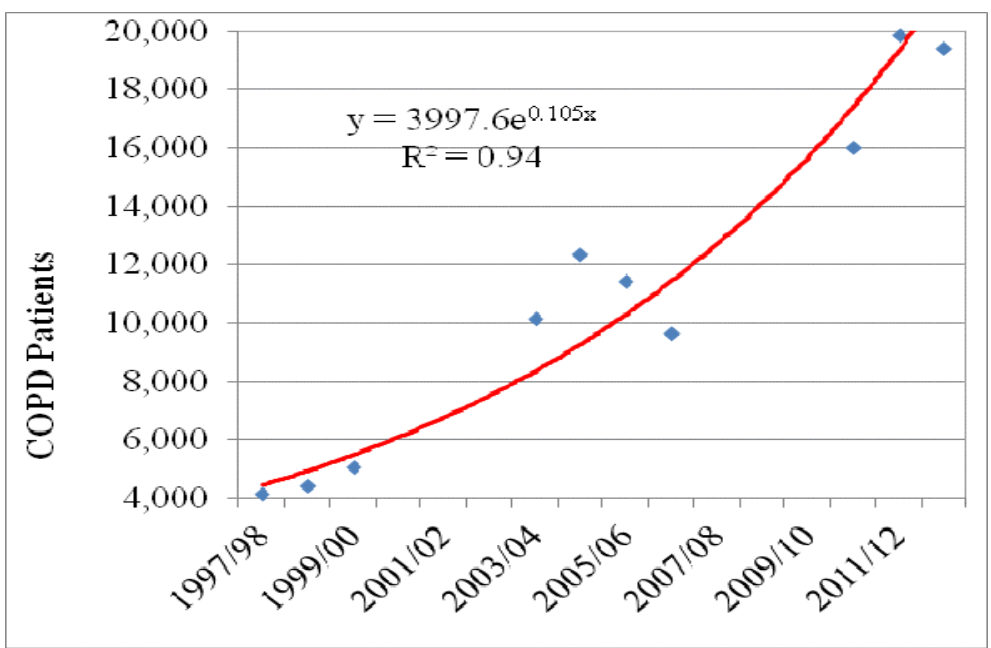

Fig. 3 A trend of COPD patients admitted in the Kathmandu Valley.

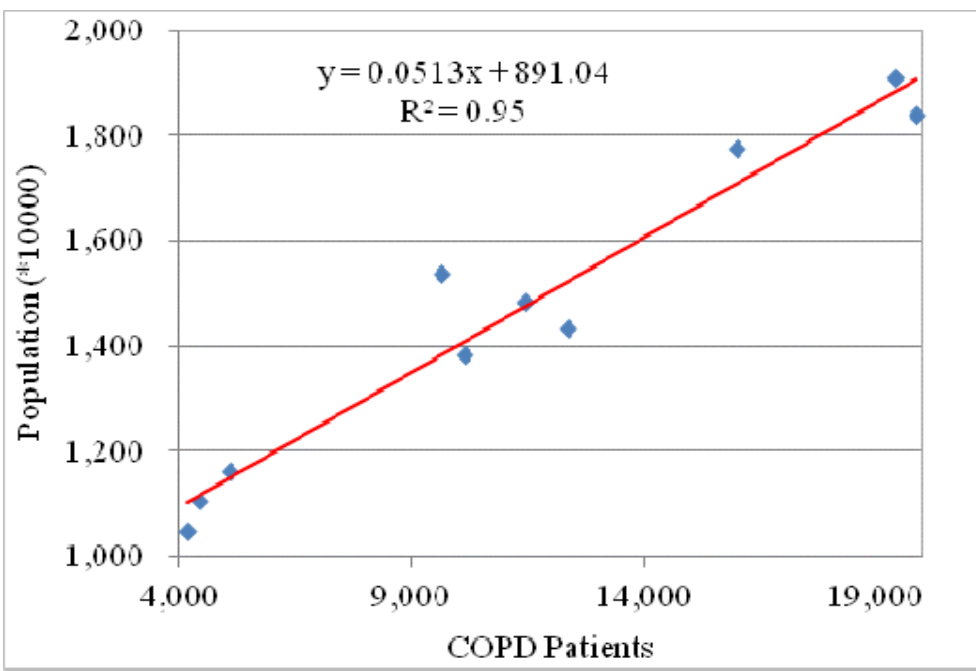

Fig. 4 Correlation between population and COPD patients.

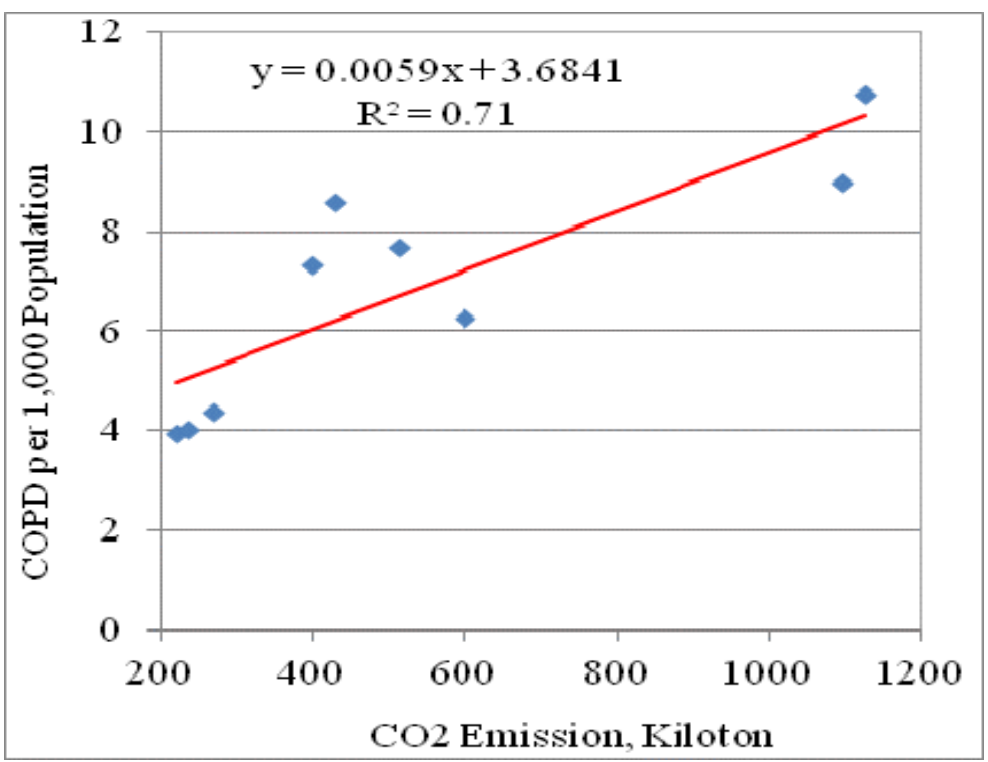

Fig. 5 A correlation between $\mathrm{COPD}$ patient and $\mathrm{CO}_{2}$ emissions. 
smog-a combination of emission smoke, dust particles, and fog - covers the valley at low level that prevents the escape of emissions from the valley. Also, because of low wind speed at that time, pollution gets cumulates, which leads to sever the air pollution. In the summer, rainy season, rain washes away pollution in the air and the pollution level reduces [7].

Table 3 shows the number of patients admitted to the "Teaching Hospital" monthwise in 2011. In total, 380 COPD patients were admitted to that hospital. Data showed that the number of COPD patients admitted in the winter was $124(36+45+43)$, and that of in the rainy season was $78(30+23+25)$. In that hospital, the monthly average number of patients admitted was 32 .

\subsection{The Kathmandu Valley and Its Shape}

The Kathmandu Valley, which is situated at elevation from $1,310 \mathrm{~m}$ to $1,400 \mathrm{~m}$ above the sea level, is surrounded by high mountains as high as $8,940 \mathrm{ft}$. from the sea level. Figs. 6 and 7 show how the valley is surrounded by high mountains. Its shape is like a bowl, and by geographical configuration of the valley, the polluted air does not get replaced by fresh air that leads to accumulated pollution which becomes severe [7]. Figs. 6 and 7 were produced by Google Earth.

Table 3 Variation of COPD patients in the Teaching Hospital in 2011.

\begin{tabular}{lll}
\hline Seasons & Months & COPD patients \\
\hline \multirow{3}{*}{ Winter } & December & 36 \\
& January & 45 \\
& February & 43 \\
\hline \multirow{3}{*}{ Spring } & March & 37 \\
& April & 35 \\
& May & 40 \\
\hline \multirow{3}{*}{ Summer } & June & 30 \\
& July & 23 \\
& August & 25 \\
\hline \multirow{3}{*}{ Autumn } & September & 22 \\
& October & 21 \\
\hline Average & November & 23 \\
\hline Total COPD patients & 32 \\
\hline
\end{tabular}

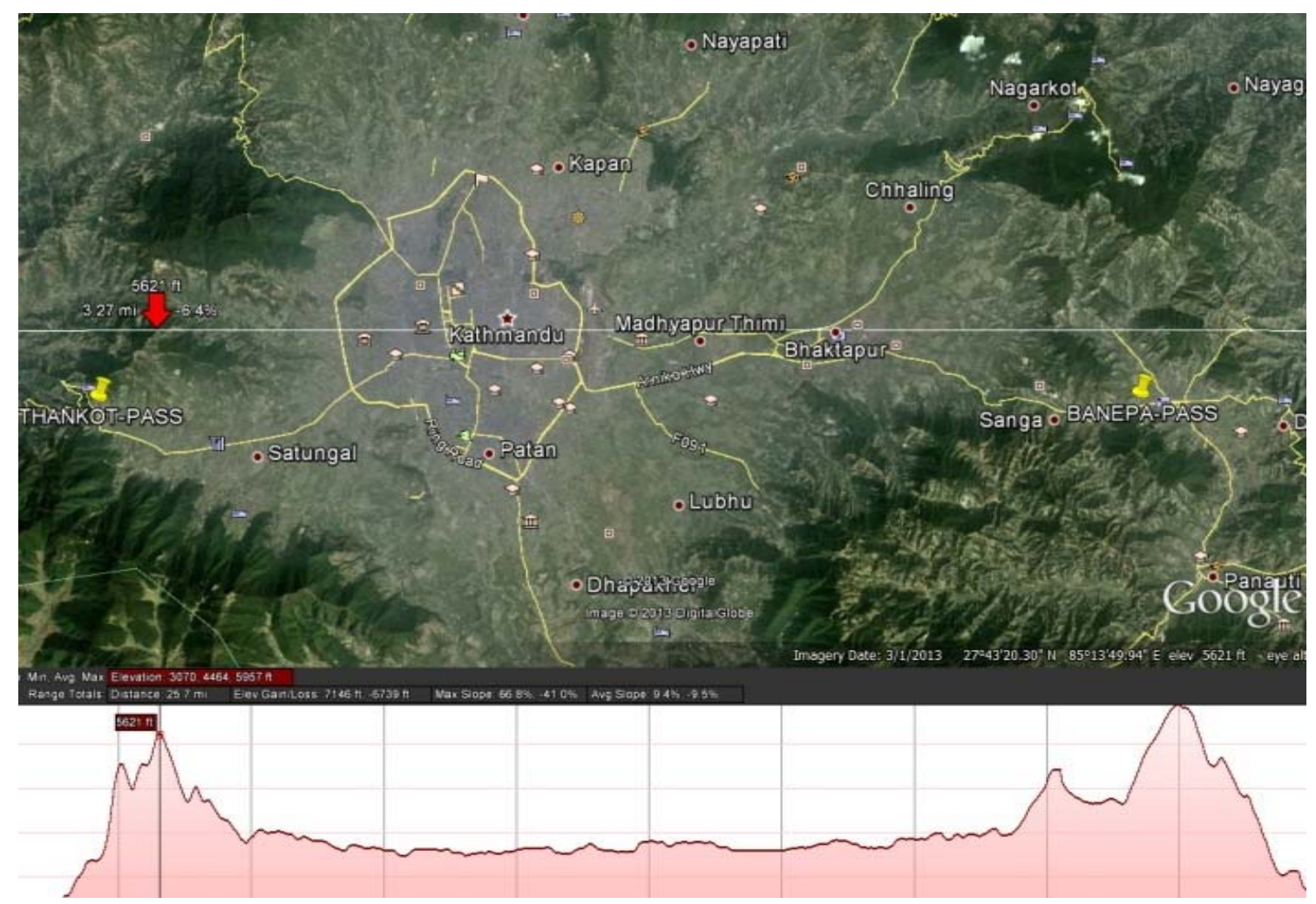

Fig. 6 East-west elevation profile of the valley. 


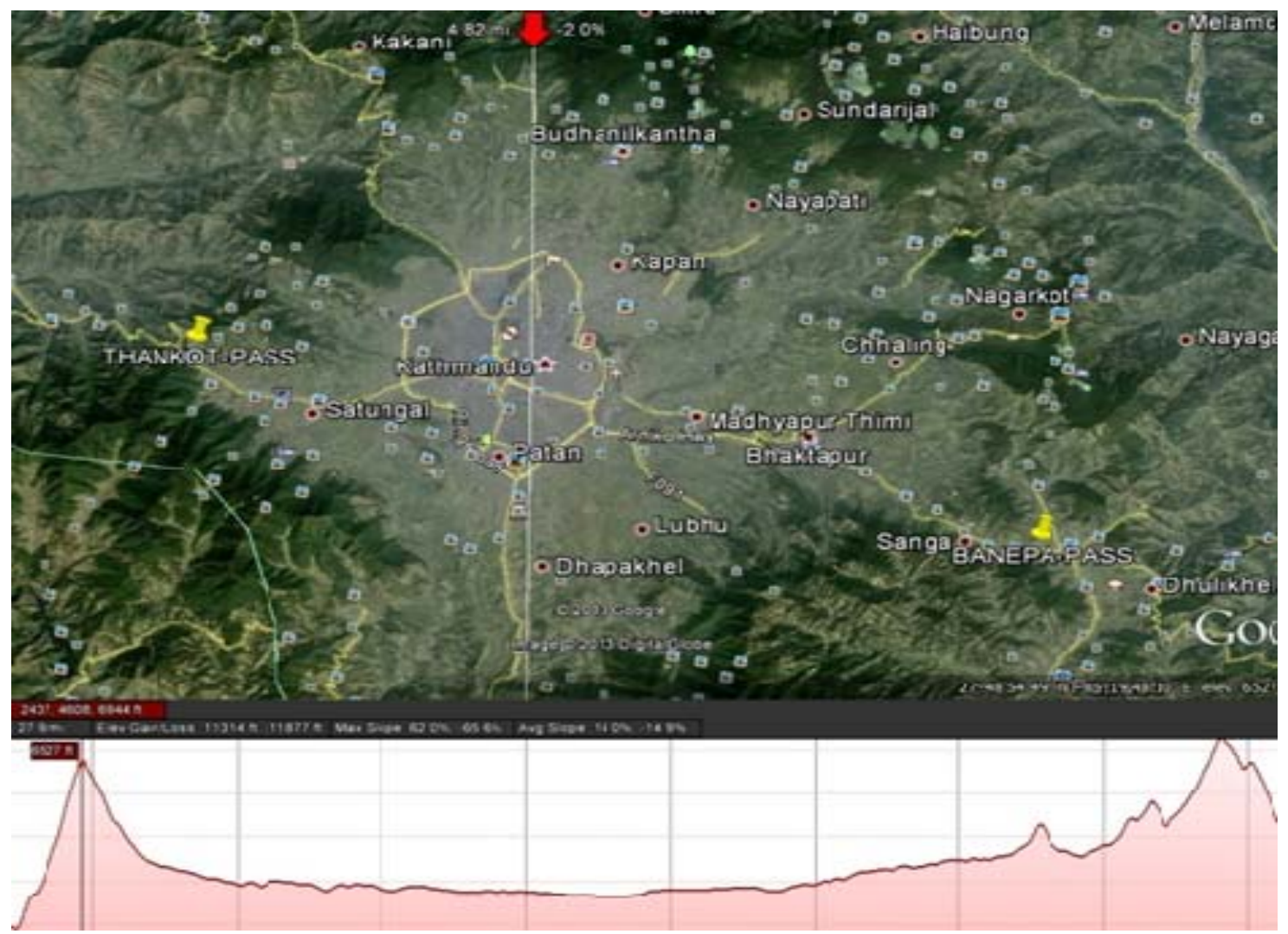

Fig. 7 North-south elevation profile of the valley.

\section{Results and Discussion}

This study has a significant impact on the calculation of the amount of $\mathrm{CO}_{2}$ emissions produced by transportation sector and its impact on health of the Kathmandu Valley residents. The vehicle registration data showed that the total number of vehicles increased by 12 times from 1990/1991 to 2010/2011. However, total road length in the valley was much less as compared to Las Vegas; the road densities of the Kathmandu Valley and Las Vegas City were calculated 1.77 and 7.60 lane kilometres per square kilometres of land, respectively [30, 31], which indicated the Kathmandu Valley has much lesser road density compared to Las Vegas. Comparing the population density of cities, the population density of the Kathmandu Valley in 2009 was 4,386/ $\mathrm{km}^{2}$, which was half that of New York City 10,434.62/ $\mathrm{km}^{2}$ [24, 25, 28-31]. Regarding the vehicle emissions, although emissions in New York were much higher than that of the Kathmandu Valley, the trend of $\mathrm{CO}_{2}$ emission in New

York was decreasing every year whereas that of the Kathmandu Valley was increasing exponentially. For the Kathmandu Valley, the $\mathrm{CO}_{2}$ emissions calculated in 2010/2011, which were 1,094 kilotons, were nearly 14 fold that of 1990/1991. Results indicated that there was a strong correlation between increasing the $\mathrm{CO}_{2}$ emissions and increasing the number of COPD patients in the hospitals. Fig. 3 shows there was an increasing trend of COPD patients admitted with the Pearson coefficient of determination $\left(\mathrm{R}^{2}\right)$ value 0.94 . Two other correlation tests between COPD patients versus population, and COPD patients per 1,000 population versus $\mathrm{CO}_{2}$ emissions were carried out with $\mathrm{R}^{2}$ values 0.95 and 0.71 , respectively. Looking into the number of COPD patients admitted in the "Bir Hospital", there was clear seasonality between $\mathrm{CO}_{2}$ emission and COPD patients admission in the 
hospital-when the $\mathrm{CO}_{2}$ emission increased, the COPD patient admission in the hospitals also increased. In 2011, the hospital record showed the maximum number of COPD patients admitted in January and the minimum number of patients admitted in October. Moreover, this study showed the air pollution level in the valley is far beyond the limitation set by the World Bank.

\section{Conclusions and Recommendations}

Many people die every year due to air pollution. For several countries and cities including the Kathmandu Valley, the air pollution became top-five leading cause of death. In the Kathmandu Valley, the number of vehicles registered tremendously rose-an increase of over 12-fold from 1990/1991 to 2010/2011. Due to the increase of vehicles, there was a proportionate amount of fossil fuels consumed, and then amount of $\mathrm{CO}_{2}$ emitted. Result shows that $\mathrm{CO}_{2}$ emission due to transportation was increasing exponentially in the Kathmandu Valley. The results also showed the number of COPD patients in the Kathmandu Valley was strongly positively correlated with the $\mathrm{CO}_{2}$ emissions from 1997/1998 to 2011/2012.

This study suggests four recommendations to reduce $\mathrm{CO}_{2}$ emissions in the Kathmandu Valley: (1) the newly introduced policies/standards should be effectively enforced [13]; (2) the government should import less carbon content fuel; (3) the government should introduce bus rapid transit or metro railway on possible routes [32, 33] and other public transportation means should be introduced, for example double decker large bus, street cable car, etc.; and (4) the government should increase and improve the existing road networks efficiently.

\section{Acknowledgments}

The authors would like to acknowledge the Kathmandu Motor Vehicles Department for providing vehicles registration data, Department of Health
Services, Bir Hospital, Teaching Hospital, and Patan Hospital for providing COPD patient records. The authors also would like to thank Mrs. Geeta Shrestha for collecting these data. Finally, the authors would like to thank Mr. Rodrigo Kenneth Gusmão Iwanaga, for his help in this study.

\section{References}

[1] The World Bank. 2003. "Health Impacts of Outdoor Air Pollution.” South Asia urban air quality management briefing paper No 11. Washington, DC, USA: The World Bank.

[2] CSE (Center for Science and Environment). 2013. Air Pollution Is Now the Fifth Largest Killer in India, Says Newly Released Findings of Global Burden of Disease Report. CSE.

[3] NIEHS (National Institute of Environmental Health Sciences). 2017. Air pollution. North Carolina: NIEHS.

[4] Holgate, S. T., Koren, H. S., Samet, J. M., and Maynard, R. L. 1999. Air Pollution and Health. London, UK: Academic Press.

[5] Rice, S. A. 2003. "Health Effects of Acute and Prolonged $\mathrm{CO}_{2}$ Exposure in Normal and Sensitive Populations.” Presented at the Second Annual Conference on Carbon Sequestration: Virginia, USA.

[6] Jha, P. K., and Lekhak, H. D. 2003. "Air Pollution Studies and Management Effects in Nepal.” Journal Pure and Applied Geophysics 160: 341-8.

[7] CEN (Clean Energy Nepal) and ENPHO (Environmental and Public Health Organization). 2003. Health Impacts of Kathmandu's Air Pollution. Washington, DC, USA: CEN and ENPHO.

[8] Jha, P. K. 2001. Transport Sector Technical Inspection System in Nepal. Kathmandu, Nepal: Tribhuvan University.

[9] Shrestha, R. M., and Rajbhandari, S. 2010. "Energy and Environmental Implications of Carbon Emission Reduction Targets: Case of Kathmandu Valley, Nepal.” International Journal Political, Economical, Planning, Environmental, Social Aspects of Energy 38 (9): 4818-27.

[10] Joshi, S. K. 2003. “Air Pollution in Nepal.” Kathmandu University Medical Journal 1 (4): 231-2.

[11] KrantiKari. 2011. "Hear Me, Fear Me. Himal Cement Factory RIP.” Accessed April 14, 2017. http://krantikarki.wordpress.com/2011/06/05/himal-ceme nt-factory-r-i-p/.

[12] Shrestha, R. M., and Malla, S. 1996. “Air Pollution from Energy Use in a Developing Country City: The Case of Kathmandu Valley, Nepal.” Journal of Energy 21 (9): 785-94. 

Its Impact on Health in the Kathmandu Valley, Nepal

[13] Dhakal, S. 2003. "Implications of Transportation Policies on Energy and Environmental in Kathmandu Valley, Nepal.”? Journal of Energy Policy 31 (14): 1493-507.

[14] Nepal Republica Media Pvt. Ltd. 2012. Govt. imposes Euro III Standards for Vehicles. Republica.

[15] Baidya, S., and Borken-Keefeld, J. 2009. "Atmospheric Emissions from Road Transportation in India.” Journal of Energy Policy 37 (10): 3812-22.

[16] NIH (National Institutes of Health). 2012. What Is COPD?. NHLBI, NIH. National Heart, Lung, and Blood Institute.

[17] Center for Disease Control and Prevention (CDC). 2015. "Chronic Obstructive Pulmonary Disease (COPD)." Center for Disease Control and Prevention. Accessed April 14, 2017. http://www.cdc.gov/copd/.

[18] Department of Health Services (DHS). 2011. Annual Report. Government of Nepal, Ministry of Health and Population; DHS: Kathmandu, Nepal, 2011.

[19] Brunekreef, B., and Holgate, S. T. 2002. "Air Pollution and Health.” The Lancet 360 (9341): 1233-42.

[20] Shrestha, P. P., Shrestha, K., and Shrestha, K. 2012. Carbon Dioxide Emissions by the Transportation Sector in Kathmandu Valley, Nepal. Texas: ASCE, 90-7.

[21] United States Environmental Protection Agency (EPA). 2005. Average Carbon Dioxide Emissions Resulting from Gasoline and Diesel fuel. Assessed April 14, 2017. https://www.chargepoint.com/files/420f05001.pdf.

[22] USEPA (United States Environmental Protection Agency). 2011. Inventory of U.S. Greenhouse Gas Emissions and Sinks: 1990-2009. Washington, DC, USA: USEPA.

[23] ICIMOD (International Center for Integrated Mountain Development). n.d. “Homepage.” Accessed April 14,
2017. http://www.icimod.org/.

[24] Planyc. 2010. Inventory of New York City Greenhouse Gas Emission. New York: The City of New York.

[25] Fact Monster. n.d. "U. S. Population by State, 1970 to 2010.” Accessed April 14, 2017. http://www.factmonster.com/ipka/A0004986.html.

[26] Mohanty, A. 2011. "State of Environment: Kathmandu Valley, Kathmandu Nepal: A Special Review.” Journal of the Institute of Engineering 8 (1 \& 2): 126-37.

[27] MHP (Ministry of Health and Population). 2011. Nepal Population Report 2011. Kathmandu, Nepal: MHP.

[28] Pant, P. R., and Dongol, D. 2009. Kathmandu Valley Profile. Kathmandu, Nepal: Kathmandu Metropolitan City.

[29] Khanal, P. 1987. "The Valley Chokes: Pollution in Kathmandu.” Himal South Asian. Accessed April 14, 2017. http://old.himalmag.com/component/content/article /3369-the-valley-chokes-pollution-in-kathmandu.html.

[30] ATS (American Thoracic Society). n.d. "What Is Chronic Obstructive Pulmonary Disease (COPD).” ATS. Accessed April 14, 2017. http://www.thoracic.org/copd-guidelines/for-patients/wha t-is-chronic-obstructive-pulmonary-disease-copd.php.

[31] City Council. 2009. The City of Las Vegas Transportation \& Streets and Highways Element of the Las Vegas 2020 Master Plan. Las Vegas, NV, USA: City Council.

[32] City of Las Vegas. 2012. Planned Streets and Highways. Las Vegas, NV, USA: City of Las Vegas.

[33] The Kathmandu Post. n.d. "Kathmandu Metro Railway Project.” Accessed April 14, 2017. http://www.ekantipur.com/the-kathmandu-post/2012/11/2 4/money/kathmandu-metro-railway-project/242086.htm. 